\title{
A quantitative real-time RT-PCR assay for mature C. albicans biofilms
}

\author{
Zhihong Xie, Angela Thompson, Helena Kashleva and Anna Dongari-Bagtzoglou*
}

\begin{abstract}
Background: Fungal biofilms are more resistant to anti-fungal drugs than organisms in planktonic form. Traditionally, susceptibility of biofilms to anti-fungal agents has been measured using the 2,3-bis(2-methoxy-4-nitro5-sulfophenyl)-2H-tetrazolium-5-carboxyanilide (XTT) assay, which measures the ability of metabolically active cells to convert tetrazolium dyes into colored formazan derivatives. However, this assay has limitations when applied to high C. albicans cell densities because substrate concentration and solubility are limiting factors in the reaction. Because mature biofilms are composed of high cell density populations we sought to develop a quantitative realtime RT-PCR assay (qRT-PCR) that could accurately assess mature biofilm changes in response to a wide variety of anti-fungal agents, including host immune cells.

Results: The XTT and QRT-PCR assays were in good agreement when biofilm changes were measured in planktonic cultures or in early biofilms which contain lower cell densities. However, the real-time qRT-PCR assay could also accurately quantify small-medium size changes in mature biofilms caused by mechanical biomass reduction, antifungal drugs or immune effector cells, that were not accurately quantifiable with the XTT assay.

Conclusions: We conclude that the GRT-PCR assay is more accurate than the XTT assay when measuring smallmedium size effects of anti-fungal agents against mature biofilms. This assay is also more appropriate when mature biofilm susceptibility to anti-fungal agents is tested on complex biological surfaces, such as organotypic cultures.
\end{abstract}

\section{Background}

Microbial biofilms have an innate resistance to antimicrobials and immune attack and have been recently linked to many recalcitrant or recurrent infections [1-3]. The ability of $C$. albicans to form biofilms on prosthetic devices and mucosal surfaces is believed to be intimately associated with its ability to trigger systemic or mucosal infection [4-6]. Therefore the development of novel anti-biofilm agents is of paramount importance in the treatment or prevention of these infections.

Susceptibility of Candida biofilms to anti-fungal agents is frequently measured using colorimetric assays that estimate metabolic activity of viable cells residing in biofilms [2,6,7]. Such assays have also been widely used to assess viable cell numbers [8-16]. In these assays metabolically active cells convert tetrazolium dyes into colored formazan derivatives that can be measured by a multi-well scanning spectrophotometer $[9,14,16-21]$. A

\footnotetext{
* Correspondence: adongari@uchc.edu

Division of Periodontology, School of Dental Medicine, University of Connecticut, Farmington, Connecticut, USA
}

key component of one of the formazan assays is sodium salt of 2,3-bis(2-methoxy-4-nitro-5-sulfophenyl)-2H-tetrazolium-5-carboxyanilide, or XTT. Mitochondrial dehydrogenases of viable cells cleave the tetrazolium ring of XTT yielding water-soluble orange formazan. The bioreduction of XTT is inefficient and can be potentiated by addition of an electron-coupling agent such as phenazine methosulfate $[9,13,16,17,19,22]$, menadione $[2,13,16,19,22]$ or coenzyme Q0 (CoQ) $[15,20,23]$.

The XTT assay has been used under various conditions for viability assessment of different organisms including mammalian cells, bacteria and fungi $[19,24]$. Its wide-spread use is due to the fact that it is simple, fast, and does not require highly specialized equipment other than a spectrophotometer. However, it is accurate only if there is a linear relationship between cell metabolic activity (or cell number) and colorimetric signal. Thus, for the assay to be quantitative, it is important to optimize several key experimental parameters (such as cell number, concentration of XTT, type and concentration of electron-coupling agent) for every organism and 
every experimental condition $[5,12,13,15]$. Assay optimization can be more challenging in mature biofilms since metabolic activity and viable cell number may not be linearly related $[12,13]$. In addition, colony counting methods of viability assessment are not appropriate for mature biofilms since they consist of multicellular hyphal organisms encased in a polysaccharide matrix, which hinders single cell colony growth. Given these facts we sought to critically examine the limitations of the XTT assay in measuring metabolic changes in mature biofilms and develop a molecular assay based on PCR for biofilm viability estimates that would overcome these limitations.

\section{Results}

We first tried to optimize the XTT assay for a wide range of Candida cell densities, which would represent different stages of biofilm growth. As shown in Figure 1A-B overall, a linear relationship between the OD450 signal and yeast cell number was observed only when yeast did not exceed $1 \times 10^{5}$ cells per well. Above this cell density, significant changes in yeast cell number (2-fold or greater) resulted in very small or undetectable differences in OD450 values. This suggests that the XTT assay would be of limited value in mature biofilms, since $C$. albicans biofilms are frequently started by seeding $\geq 1 \times 10^{5}$ yeast cells per well, in 96 well plates, and grown for $48 \mathrm{~h}$ or longer for biofilms to mature $[2,6,28]$.

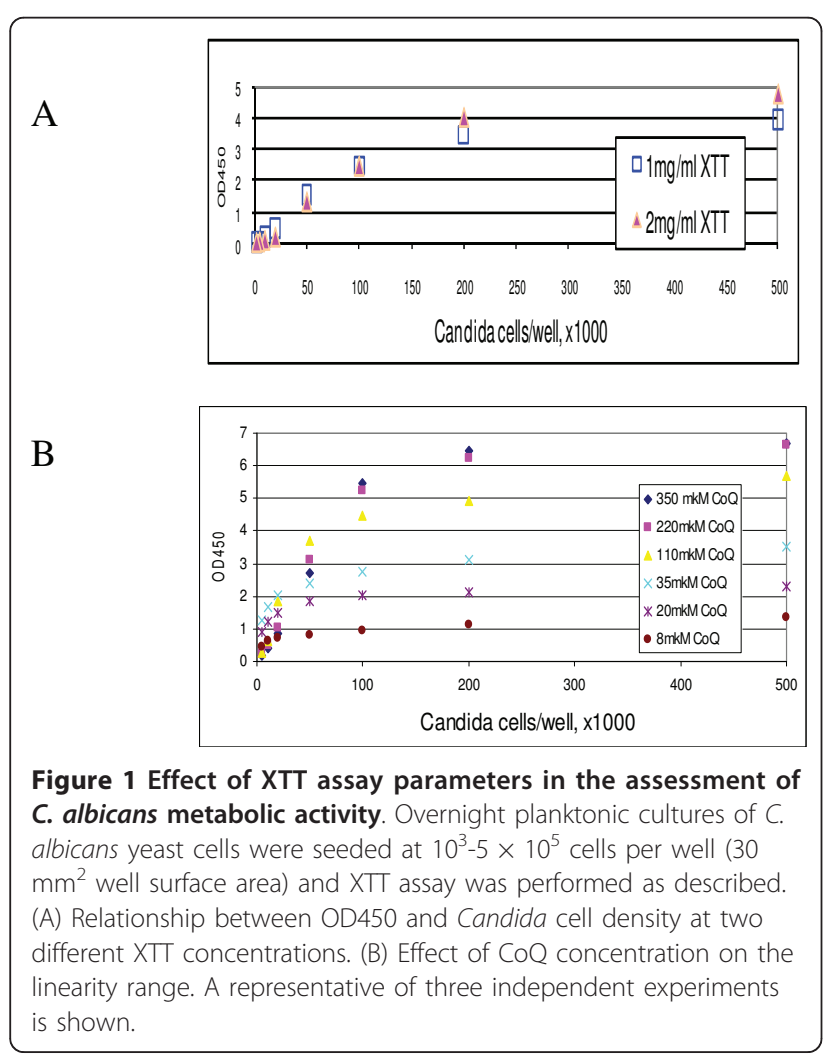

Increasing the concentration of XTT up to $2 \mathrm{mg} / \mathrm{ml}$ (since XTT maximum solubility in water is $2.5 \mathrm{mg} / \mathrm{ml}$ ) did not result in a change in OD450 when the seeding yeast cell number was equal to or lower than $1 \times 10^{5}$ cells per well (Figure 1A). With yeast cell numbers higher than $1 \times 10^{5}$ cells per well, increasing the concentration of XTT resulted in higher OD450 values, which extended the linearity range only up to $2 \times 10^{5}$ cells per well. This suggests that XTT solubility and final concentration are limiting factors in this reaction, especially when large numbers of yeast cells are used to start biofilms.

We also investigated if varying the concentration of the electron-coupling agent CoQ $(8-350 \mu \mathrm{M})$ would allow us to extend the linearity range of the XTT signal. XTT conversion rates were slower at lower concentrations of $\mathrm{CoQ}$, generating flat slopes (Figure 1B). However, we found that increasing the concentration of $\mathrm{CoQ}$ would not increase the linearity range (Figure 1B). Reading the plates at $490 \mathrm{~nm}$ as opposed to $450 \mathrm{~nm}$ or increasing the XTT reaction time to 3 hours still did not improve the linearity range (data not shown), since reaction time in higher cell densities $\left(>10^{6}\right.$ cells/well) was typically very fast (less than $10 \mathrm{~min}$ ). Collectively, these data suggest that the XTT assay cannot be adequately optimized to accommodate the cell numbers present in mature biofilms.

To further address this issue we developed a molecular assay for biofilm assessment based on quantitation of EFB1 gene transcripts in Candida cells, since the EF-1 $\beta$ protein is critical in regulating cell protein translation rates and growth [25]. The EFB1 primer pairs specifically amplified PCR products of the predicted size (136 bp) from C. albicans cDNA and gave no PCR product when tested with HL-60 cell cDNA (data not shown). To generate standard curves amplification of serially diluted plasmid pEFB was monitored by fluorescence versus cycle number curves. The assay could detect $1 \mathrm{fg}$ of pEFB, which is equivalent to 224.37 copies of pEFB.

Comparison of the two assays in quantifying viable cells at a wide range of seeding cell densities showed that in contrast to the XTT assay, which gave a flat colorimetric signal for cell densities exceeding $4 \times 10^{5} / 30 \mathrm{~mm}^{2}$ of surface area, the new assay was able to quantify cells at densities up to $8 \times 10^{7} / 30 \mathrm{~mm}^{2}$ (Figure $2 \mathrm{~A}-\mathrm{B}$ ). In fact, two fold differences in viable cells were accurately quantified at seeding densities ranging between $4 \times 10^{4}-8 \times 10^{7} / 30$ $\mathrm{mm}^{2}$ with the qRT-PCR assay (Figure 2B).

To further assess the accuracy of the qRT-PCR assay we compared it to viable colony counts, as well as to the XTT assay, in detecting viability changes in planktonic cells triggered by fluconazole or caspofungin. As shown in Figure 3, the qRT-PCR assay could accurately quantify a dose-dependent antifungal drug toxicity in 


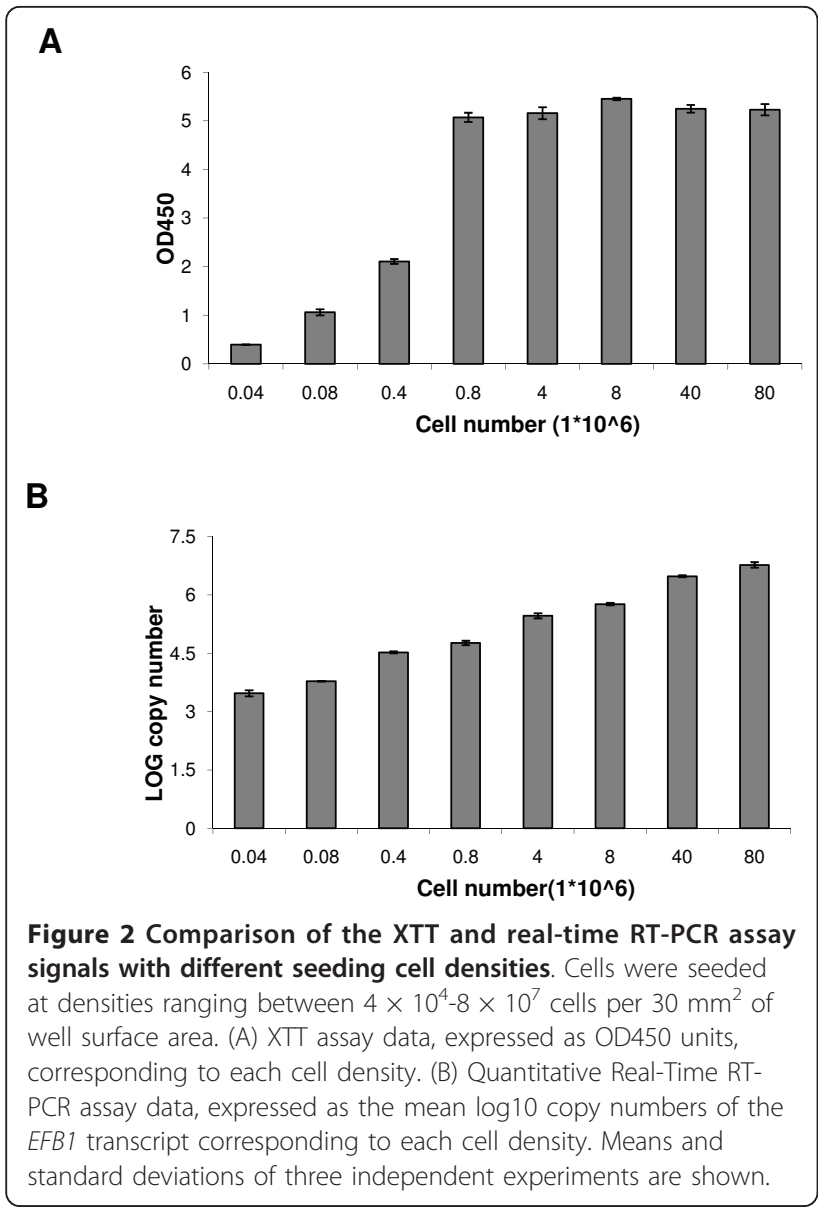

planktonic cells and was in good agreement with the $\mathrm{XTT}$ and CFU assays (Figure 3). Our data also show that the XTT and qRT-PCR assays were in good agreement in quantifying toxicity in early biofilms triggered by amphotericin $\mathrm{B}$, whereas organisms killed by heat produced no signal in the XTT or qRT-PCR assay (Figure 4). The latter was confirmed by the absence of CFU's in Sabouraud agar plates.

In order to compare the ability of the XTT and qRTPCR assays to accurately quantify changes in viable mature biofilms, the biomass of biofilms grown for 48 hours was mechanically reduced and remaining biofilm cells were assessed with the two assays. The XTT assay showed that removal of $25-50 \%$ of the biofilm mass resulted in a detectable decrease in OD450 values, compared to intact biofilm. However, there were no significant differences in the XTT signals resulting from removal of different biofilm amounts, thus the XTT signal reduction was not commensurate to the reductions in biomass. This shows that the XTT assay cannot accurately quantify changes in mature biofilms (Figure 5A). In contrast, the qRT-PCR assay showed excellent agreement with reduction in the biofilm mass since $25 \%$, $33 \%$

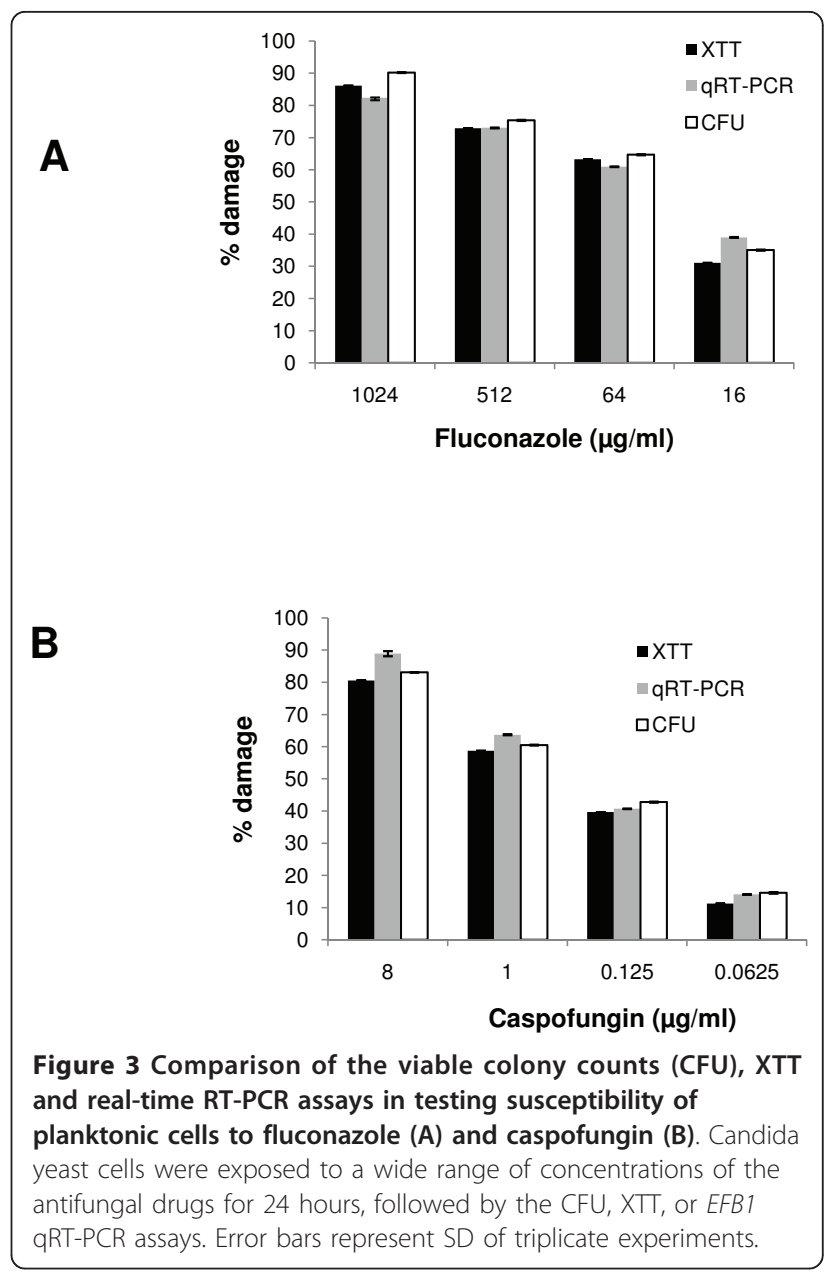

and $50 \%$ biofilm removal resulted in an average of $25.8 \%, 35.4 \%$ and $49.8 \%$ reduction in the logarithmic EFB1 transcript copy numbers, respectively (Figure 5B). This confirms the ability of the real-time RT-PCR assay to accurately measure reduction in biofilm metabolic activity in mature biofilms.

Neutrophils exhibit potent candidacidal activities in vitro $[26,27]$ and interact with Candida biofilms forming on mucosal tissues in vivo [4]. However there is a paucity of information regarding the outcome of the interactions of neutrophils with biofilm organisms [28]. One of the difficulties in studying these interactions in vitro is the shortage of quantitative assays to accurately assess neutrophil-inflicted damage in mature biofilms. Therefore, we compared the ability of the two assays to detect and quantify damage inflicted to early and mature biofilms by HL-60 cells, a human neutrophil-like cell line.

When HL-60 cells interacted with early $(3 \mathrm{~h})$ biofilms, significant biofilm damage (up to $80 \%$ ) could be detected at 10:1 effector to target ratio, regardless of the assay used to measure viable biofilm changes (Figure $6 \mathrm{~A}, \mathrm{~B})$. Significant dose response differences to the 


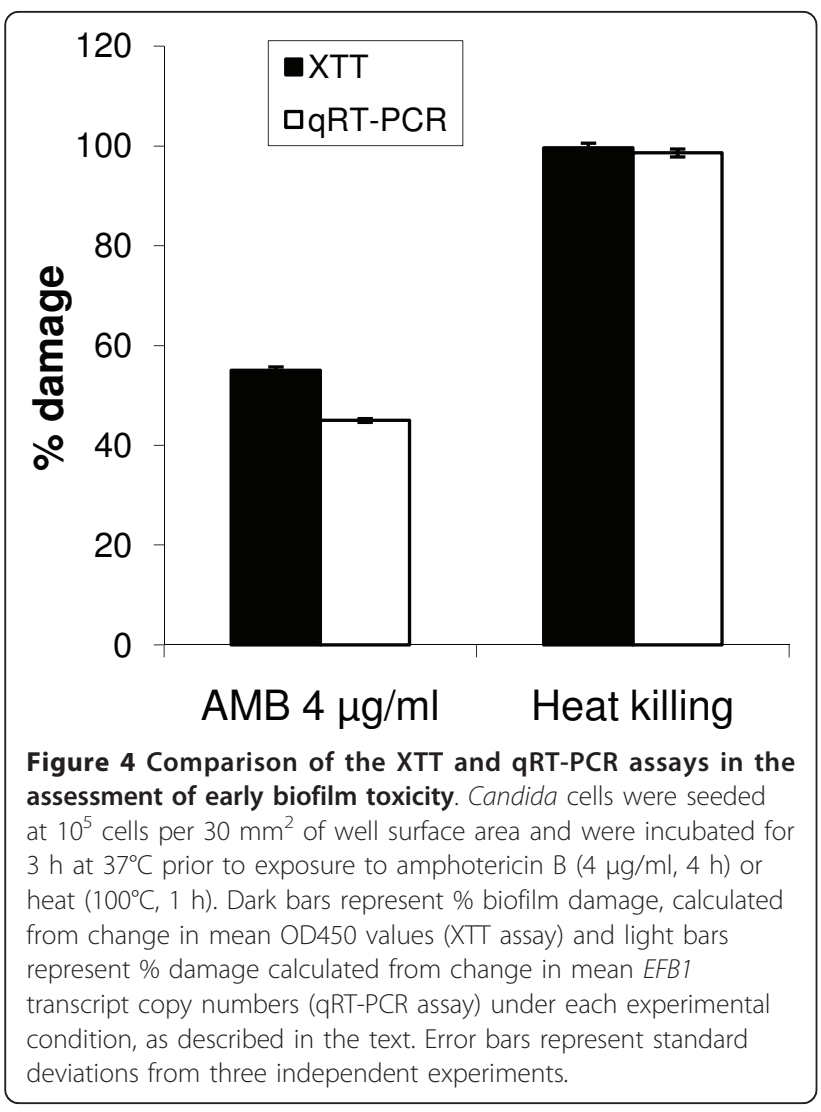

number of effectors could also be detected with both assays in early biofilms. Thus there was close agreement between the two assays when early biofilms were tested. However, in mature biofilms the XTT assay revealed overall less than $25 \%$ fungal damage by immune effectors and produced similar signals regardless of the number of effectors present, although there was a slight indication of a dose response (Figure 6A). In contrast, the real-time RT-PCR assay revealed a more robust dose response of mature biofilms to immune effectors, with damage to mature biofilms ranging approximately between $10-45 \%$, depending on the effector to target ratio (Figure 6B). Nevertheless, regardless of the assay, early biofilms exhibited significantly higher susceptibility to neutrophil-like cells than mature biofilms, consistent with a recent report [28].

We next compared the performance of the XTT and qRT-PCR assays in quantifying viability changes in mature biofilms grown on a three dimensional model of the human oral mucosa. In order to do this we measured the effects of three antifungal drugs with different mechanisms of action, as well as damage inflicted by human leukocytes to mucosal biofilms. As expected, the data showed that the XTT assay underestimates damage to mature biofilms in this system, when smaller levels of biofilm toxicity are measured, such as the ones obtained

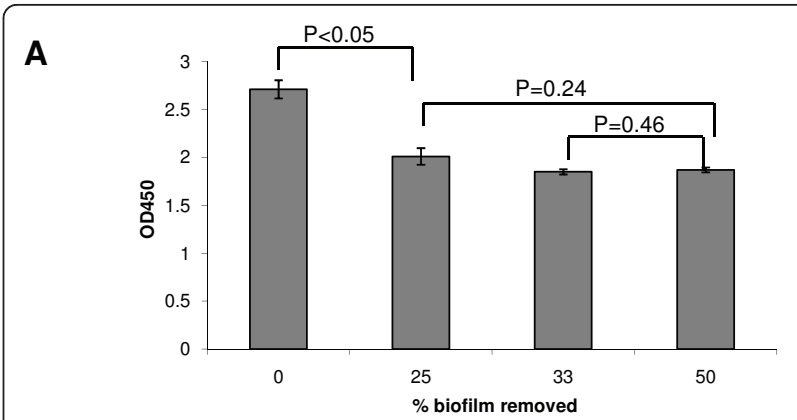

B

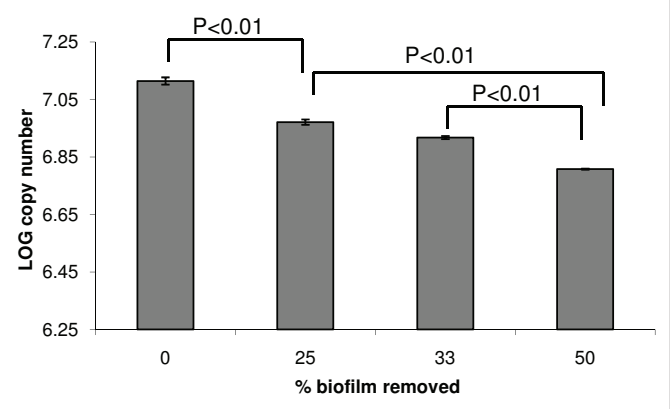

Figure 5 Comparison of the XTT and qRT-PCR assays in assessing biomass reduction in mature biofilms. Biofilms were seeded at $10^{5}$ cells per $30 \mathrm{~mm}^{2}$ of well surface area and were incubated for $48 \mathrm{~h}$. Prior to assessment, biofilms were either left intact (0), or were mechanically reduced by $25 \%, 33 \%$ or $50 \%$, followed by the XTT assay (A) or qRT-PCR assay (B). Error bars represent SD of triplicate experiments. Student t-test $p$ values are shown on the graph for each set of comparisons.

with fluconazole, caspofungin or leukocytes (Figure 7A). In contrast, the qRT-PCR assay revealed significant Candida toxicity by all antifungal agents tested, which was consistent with the limited levels of Candida tissue invasion into the submucosal compartment in the presence of these agents (Figure 7B).

\section{Discussion}

Real-Time PCR technologies combine the sensitivity of conventional PCR with the generation of a quantifiable fluorescent signal and have been increasingly used to assess viability of microorganisms [11,29-31]. Quantitative real-time PCR allows for the detection of PCR products produced at each step of the reaction, since an increase in reporter fluorescent signal is directly proportional to the number of amplicons generated. As we have done in this work, PCR products can be quantitated by generating a standard curve, in which the absolute concentration of the plasmid standard is known.

In this study we measured the effect of anti-fungal agents against mature biofilms with a real-time RTPCR assay based on the quantification of EFB1 


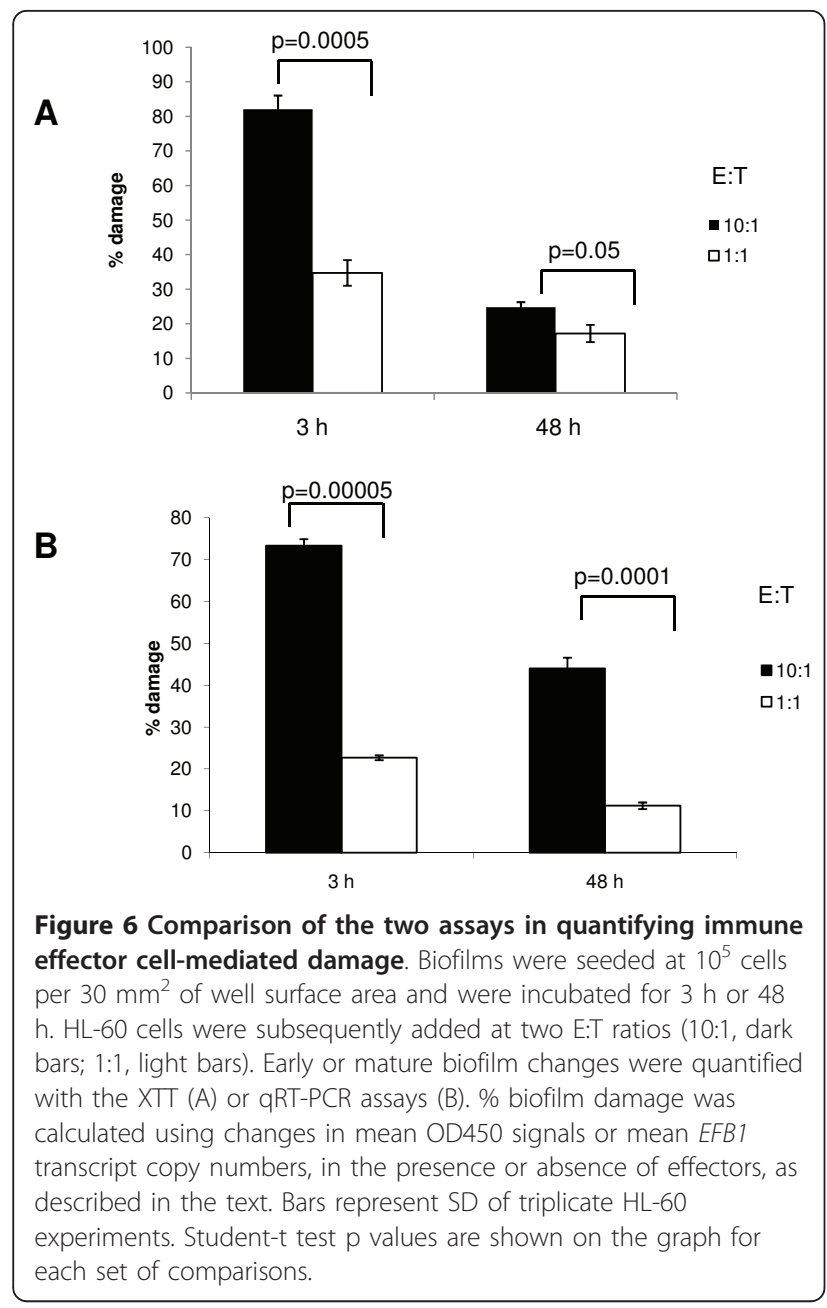

transcript copy numbers in biofilm cells. The EFB1 gene is constitutively expressed under most growth conditions and is frequently used as a normalization gene in real-time RT-PCR quantification of other Candida genes [32-37]. By designing sense primers that span an intron splice site in the EFB1 sequence, we expected that only intact mRNA molecules would serve as a template in the RT-PCR assay and that these molecules would be degraded following the death of the organisms in the biofilm. Our results with this molecular assay are consistent with our expectations and show that it is highly quantitative in a wider range of seeding fungal cell densities and that it more accurately measures small-moderate mature biofilm changes in response to stressors, compared to the traditional XTT assay. We have also shown that this assay is particularly well suited for fungal biofilm viability estimates in complex biological systems containing immune effectors or mucosal cell cultures. This may be partly due to the fact that mammalian cells also metabolize XTT, which further limits substrate availability [19].

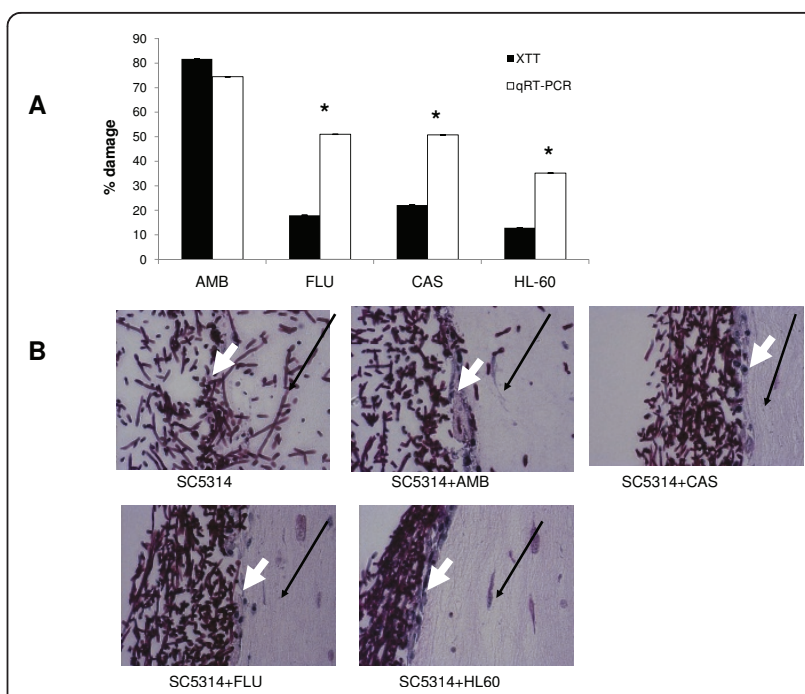

Figure 7 Biofilm susceptibility testing on a three dimensional oral mucosal culture. Candida biofilms were grown for $24 \mathrm{~h}$ and subsequently exposed to antifungal drugs $(4 \mu \mathrm{g} / \mathrm{ml}$ amphotericin B, $70 \mu \mathrm{g} / \mathrm{ml}$ fluconazole or $8 \mathrm{\mu g} / \mathrm{ml}$ caspofungin) or neutrophil-like $\mathrm{HL}$ 60 cells at an effector to target cell ratio of 10:1, for 24 additional hours. (A) The effects of antifungal agents on biofilms were quantitatively assessed by the XTT and QRT-PCR assays. Results represent the mean \pm SD of one representative experiment where each condition was set up in triplicate. ${ }^{*} p<0.01$ for comparison between XTT and qRT-PCR in each condition. (B) PAS stain of histologic sections showing the ability of the biofilm organisms to invade into the submucosal compartment after exposure to antifungal drugs or leukocytes. Black arrows: submucosal compartment. White arrows: epithelial layer. Microorganisms appear in dark blue.

Compared to the XTT assay, the real-time assay is more technically demanding, more prone to experimental errors due to the multiple additional steps required in sample preparation, more costly, and significantly more time consuming. Thus it should be reserved for susceptibility testing of mature biofilms growing in complex biological model systems containing immune effectors or mucosal cells or used as a confirmatory assay when small changes in mature biofilms are detected with the XTT assay.

\section{Conclusions}

In conclusion, our results indicate that the XTT assay has to be applied with caution to biological systems containing large numbers of organisms alone or in combination with mammalian cells. We also conclude that molecular assessment of biofilms based on quantitation of EFB1 transcripts is a sensitive, reproducible and quantitative method to measure the damaging effect of anti-fungal agents against mature biofilms. The new quantitative assay will aid in further investigations of the mechanisms of Candida biofilm resistance to immune effector cells, which are presently unknown. In addition the new assay can be applied in quantitative assessment of mature 
biofilm susceptibility to novel anti-biofilm therapeutic agents that are applied topically on mucosal surfaces.

\section{Methods \\ Biofilm Growth}

Strain C. albicans SC5314 was used in this study [38]. Yeast from frozen stocks were maintained on YPD agar plates. For experimentation, yeast were inoculated into YPD broth supplemented with $2 \%$ dextrose and grown overnight at $24^{\circ} \mathrm{C}$ with shaking. Biofilms were grown by seeding C. albicans blastoconidia in flat bottom well plates (Becton Dickinson, Franklin Lakes, N.J.) and incubating at $37^{\circ} \mathrm{C}$ from $3 \mathrm{~h}$ to $48 \mathrm{~h}$. In preliminary work, five different seeding media (YNB-0.5\% glucose, DMEM, DMEM-5\%FBS, DMEM-10\%FBS and RPMI-10\%FBS) were tested. Microscopic observations showed that the best attachment of biofilms to plastic was achieved in DMEM-10\%FBS. Thus we used DMEM-10\%FBS (Biowest/USA Scientific) in all experiments that followed.

To grow biofilms under conditions resembling in vivo mucosal biofilm development a three dimensional model of the human oral mucosa, developed in our laboratory, was used which faithfully mimics the oral mucosal tissue architecture in vivo [39]. Briefly, this model system is composed of 3T3 fibroblasts embedded in a biomatrix of collagen type I, overlaid by a multilayer of well-differentiated oral epithelial cells (OKF6/ TERT-1). C. albicans cells $\left(1 \times 10^{6}\right.$ yeast cells $)$ were added to the cultures apically in $100 \mu \mathrm{l}$ of airlift medium without FBS and antibiotics and incubated for $24 \mathrm{~h}$. To assess mucosal tissue damage and invasion tissues were formalin-fixed, embedded in paraffin and $5 \mu \mathrm{m}$ sections were stained with the Periodic Acid Schiff (PAS) stain.

\section{XTT Assay}

The XTT assay was performed as we described earlier [7]. Briefly, media were aspirated from biofilms and were replaced with $100 \mu \mathrm{l} /$ well of XTT solution (Sigma Chemical Co., St. Louis, MO) containing Coenzyme Q0 (CoQ, Sigma Chemical Co., St. Louis, MO). Fresh mixtures of XTT and CoQ [1 mg/ml and $40 \mu \mathrm{g} / \mathrm{ml}$ (or 220 $\mu \mathrm{M})$, respectively, unless otherwise indicated] were prepared for each experiment. Plates were incubated at $37^{\circ}$ $\mathrm{C}$ for up to 3 hours, after which supernatants were transferred into new plates, and optical densities (OD) were measured by an Opsys Microplate Reader (Thermo Labsystems, Franklin, MA) at $450-490$ nm, with a 630 $\mathrm{nm}$ reference filter. When optical densities were higher than the limits of the microplate reader, dilutions of the supernatants in water were made.

\section{Quantitative Real-Time RT-PCR Assay}

To quantify changes in viable biofilms using an alternative approach, we measured mRNA expression of the translation elongation factor- $1 \beta$ (EF- $1 \beta)$, encoded by the EFB1 gene in C. albicans, by real-time quantitative RTPCR. The choice of this gene was based on these facts: a) fungal cells transcriptionally regulate components of their translational machinery according to external stresses that affect protein synthesis [25,36]; b) the number of $E F B 1$ gene transcripts did not change significantly during biofilm or planktonic growth between $3 \mathrm{~h}$ and 48 $\mathrm{h}$ (not shown); and c) EFB1 is frequently used as a housekeeping gene in real-time RT-PCR quantification of other Candida genes [29,32,33,36]. Total RNA from biofilms was isolated using the RiboPure yeast kit (Ambion, Inc.), according to the manufacturer's instructions. RNA concentrations and purity were determined by measuring the absorbance at $260 \mathrm{~nm}$ and $280 \mathrm{~nm}$ (ND-1000 spectrophotometer, NanoDrop Technologies). Equal amounts of RNA (3 $\mu \mathrm{g}$ in $20 \mu \mathrm{l}$ reactions) were reverse transcribed with oligo(dT) primers using Superscript reverse transcriptase II (Invitrogen).

Primers were based on the published sequence of the $E F B 1$ gene of $C$. albicans. Primer sequences used were as follows: Forward: 5'- CAT TGA TGG TAC TAC TGC CAC -3'; Reverse: 5' - TTT ACC GGC TGG CAA GTC TT -3'. The forward primer spanned the sole exon-exon boundary of EFB1, thus excluding amplification of genomic $C$. albicans DNA. The uniqueness of the primers for $C$. albicans EFB1 was determined using the BLAST database http://www.tigr.org.

To generate standard curves for quantitative analyses a pEFB plasmid was prepared as follows. A 136-bp C. albicans EFB exon fragment, containing the target sequence, was amplified with the above mentioned primers. PCR was performed in a DNA thermal cycler with 1 cycle of $5 \mathrm{~min}$ at $95^{\circ} \mathrm{C} ; 40$ cycles of $1 \mathrm{~min}$ at $95^{\circ} \mathrm{C}$, $30 \mathrm{~s}$ at $62^{\circ} \mathrm{C}, 30 \mathrm{~s}$ at $72^{\circ} \mathrm{C}$; and a final extension at $72^{\circ} \mathrm{C}$ for $5 \mathrm{~min}$. This fragment was ligated into the pCR 2.1 plasmid vector $(3.931 \mathrm{~kb})$ and transformed into One Shot cells (Top10F') using a TA cloning kit (Invitrogen). Plasmids were digested with $x h o$ I to generate a linear template and purified with the PureYield ${ }^{\text {TM }}$ Plasmid Miniprep System (Promega). Plasmid concentrations were determined spectrophotometrically and copy numbers calculated based on linear plasmid mass. Serial plasmid dilutions ( $500 \mathrm{pg}, 50 \mathrm{pg}, 5 \mathrm{pg}, 500 \mathrm{fg}, 50 \mathrm{fg}, 5$ $\mathrm{fg}, 1 \mathrm{fg}$ of DNA/ $\mu \mathrm{l}$ ) were then used to generate standard curves for detection and quantification of EFB1 mRNA by the iCycler iQ RT-PCR assay.

Real-time PCR was performed with an iCycler iQ realtime PCR detection system (Bio-Rad). All PCR reaction mixtures contained the following: $10 \mu \mathrm{l} 2 \times \mathrm{iQ}^{\mathrm{TM}} \mathrm{SYBR}^{\circledR}$ Green Supermix (BioRad, Hercules, CA), $1 \mu \mathrm{l}$ of firststrand cDNA reaction mixture or linear plasmid DNA, $0.1 \mu \mathrm{M}$ of primers and $\mathrm{H}_{2} \mathrm{O}$ to bring the final volume to $20 \mu \mathrm{l}$. The program for amplification had an incubation 
step at $50^{\circ} \mathrm{C}$ for $2 \mathrm{~min}$, and $95^{\circ} \mathrm{C}$ incubation for $5 \mathrm{~min}$, followed by 40 cycles of $95^{\circ} \mathrm{C}$ for $10 \mathrm{~s}$ and $62^{\circ} \mathrm{C}$ for $30 \mathrm{~s}$. Reactions to estimate transcript copy number were run in duplicate from two biologic RNA replicates. Data were analyzed using the iCycle iQ system software (BioRad).

\section{Testing of planktonic cells}

Candida cells were grown overnight in YPD broth as described above. Cultures were adjusted to a cellular density equivalent to $1.0 \times 10^{6} \mathrm{cells} / \mathrm{ml}$ and subjected to caspofungin (CAS, Merck Research Laboratories, Rahway, N.J.) or fluconazole (FLU, Pfizer Inc., Sandwich, United Kingdom) treatment for $24 \mathrm{~h}$, at doses ranging from $0.0625-1024 \mu \mathrm{g} / \mathrm{ml}[40,41]$. Untreated cells served as negative controls. Four replicates were included in each experiment. The effects of the anti-fungals on planktonic cells were measured by colony counts on Sabouraud agar plates (CFU), or by the XTT and qRTPCR assays as described above.

\section{Biofilm testing}

To compare the ability of the two assays to quantify changes in mature biofilms stemming from biomass reduction, organisms were grown in 12 well plates for $48 \mathrm{~h}$ and their biomass was physically reduced by removing $50 \%, 33 \%$ or $25 \%$ of the biofilm from the well surface. To perform this, the round surface area of each well was divided into two, three or four equal parts, and removal of the biofilm from $1 / 2,1 / 3$ or $1 / 4$ of the surface area was accomplished with the help of a modified rubber policeman, with a sweeping edge cut to the size of the well radius. Remaining biofilm cells observed microscopically were removed using a sterile glass suction tip. XTT and real-time RT-PCR measurements in residual biofilms in these wells were subsequently compared to intact biofilms.

To compare the ability of the two assays to quantify changes in viable biofilms in response to different stressors, biofilms grown on plastic were exposed to pharmacologic [amphotericin B (AMB), $4 \mu \mathrm{g} / \mathrm{ml}, 4 \mathrm{~h}$ ], environmental $\left(100^{\circ} \mathrm{C}, 1 \mathrm{~h}\right)$ or immune cell stressors and viability was measured by the XTT or qRT-PCR assays. To quantify susceptibility to immune cellinflicted damage we used a neutrophil-like cell line (HL60, ATCC), as previously described [7]. Briefly, pre-activated HL-60 cells (1.25\% DMSO for 7-9 days) were added to biofilms at varying effector to target cell ratios, based on seeding cell densities. After incubation at $37^{\circ} \mathrm{C}$, $5 \% \mathrm{CO}_{2}$ for 2 hours, media were aspirated, HL-60 cells were lysed with sterile $\mathrm{H}_{2} \mathrm{O}$, and fungal viability was assessed with the XTT or qRT-PCR assays. Biofilms grown on mucosal tissues were exposed to anti-fungal drugs $(4 \mu \mathrm{g} / \mathrm{ml}$ amphotericin $\mathrm{B}, 70 \mu \mathrm{g} / \mathrm{ml}$ fluconazole or $8 \mu \mathrm{g} / \mathrm{ml}$ caspofungin $[40,41])$ or HL-60 cells for
24 hours, followed by mammalian cell lysis with sterile water. This was followed by the XTT or qRT-PCR assays. Anti-biofilm activity was calculated according to the following formula: \% fungal damage $=(1-x / n) * 100$, where $\times$ is the OD450 or EFB1 transcript copy number of experimental wells $(C$. albicans with stressors/effectors) and $\mathrm{n}$ is the OD450 or EFB1 transcript copy number of control wells (C. albicans only). All experiments were performed in triplicate.

\section{Acknowledgements}

This study was supported by NIH/NIDCR grant R01 DE13986 to ADB and in part by a General Clinical Research Center grant from NIH (M01RR06192) awarded to the University of Connecticut Health Center, Farmington, CT.

\section{Authors' contributions}

ZX participated in the design of the study, performed the experimental procedures, carried out the data analysis, and drafted the manuscript. AT and $\mathrm{HK}$ helped in certain experimental procedures. ADB conceived the study and helped to draft the manuscript. All authors read and approved the final manuscript.

\section{Competing interests}

The authors declare that they have no competing interests.

Received: 30 June 2010 Accepted: 6 May 2011 Published: 6 May 2011

\section{References}

1. Akiyama H, Hamada T, Huh WK, Yamasaki O, Oono T, Fujimoto W Iwatsuki K: Confocal laser scanning microscopic observation of glycocalyx production by Staphylococcus aureus in skin lesions of bullous impetigo, atopic dermatitis and pemphigus foliaceus. $\mathrm{Br} J$ Dermatol 2003, 148:526-532.

2. Chandra J, Mukherjee PK, Leidich SD, Faddoul FF, Hoyer LL, Douglas LJ, Ghannoum MA: Antifungal resistance of candidal biofilms formed on denture acrylic in vitro. J Dent Res 2001, 80:903-908.

3. Swidsinski A, Weber J, Loening-Baucke V, Hale LP, Lochs H: Spatial organization and composition of the mucosal flora in patients with inflammatory bowel disease. J Clin Microbiol 2005, 43:3380-3389.

4. Dongari-Bagtzoglou A, Kashleva H, Dwivedi P, Diaz P, Vasilakos J: Characterization of Mucosal Candida albicans Biofilms. PLOS ONE 2009, 4.

5. Mukherjee P, Zhou G, Munyon R, Ghannoum MA: Candida biofilm: a welldesigned protected environment. Med Mycol 2005, 43:191-208.

6. Ramage G, Martinez JP, Lopez-Ribot JL: Candida biofilms on implanted biomaterials: a clinically significant problem. FEMS Yeast Res 2006, 6:979-986

7. Dongari-Bagtzoglou A, Villar CC, Kashleva H: Candida albicans-infected oral epithelial cells augment the anti-fungal activity of human neutrophils in vitro. Med Mycol 2005, 43:545-549.

8. Freimoser F, Jakob CA, Aebi M, Tuor U: The MTT [3-(4,5-dimethylthiazol-2yl)-2,5-diphenyltetrazolium bromide] assay is a fast and reliable method for colorimetric determination of fungal cell densities. App/ Environ Microbiol 1999, 65:3727-3729.

9. Hawser S, Jessup C, Vitullo J, Ghannoum MA: Utility of 2,3-bis(2-methoxy4-nitro-5-sulfophenyl)-5-[(phenyl-amino)carbonyl]-2H-tetrazolium hydroxide (XTT) and minimum effective concentration assays in the determination of antifungal susceptibility of Aspergillus fumigatus to the lipopeptide class compounds. J Clin Microbiol 2001, 39:2738-2741.

10. Hawser S, Norris H, Jessup CJ, Ghannoum MA: Comparison of a 2,3-bis(2methoxy-4-nitro-5-sulfophenyl)-5-[(phenylamino)carbonyl]-2Htetrazolium hydroxide (XTT) colorimetric method with the standardized National Committee for Clinical Laboratory Standards method of testing clinical yeast isolates for susceptibility to antifungal agents. J Clin Microbiol 1998, 36:1450-1452.

11. Hayden K, Rizzo D, Tse J, Garbelotto M: Detection and quantification of Phytophthora ramorum from California forests using a real-time polymerase chain reaction assay. Phytopathology 2004, 94:1075-1083. 
12. Kuhn D, Balkis M, Chandra J, Mukherjee PK, Ghannoum MA: Uses and limitations of the XTT assay in studies of Candida growth and metabolism. J Clin Microbiol 2003, 41:506-508.

13. Meletiadis J, Mouton JW, Meis JF, Bouman BA, Donnelly JP, Verweij PE: Colorimetric assay for antifungal susceptibility testing of Aspergillus species. J Clin Microbiol 2001, 39:3402-3408.

14. Meletiadis J, Mouton JW, Meis JF, Bouman BA, Donnelly JP, Verweij PE: Comparison of spectrophotometric and visual readings of NCCLS method and evaluation of a colorimetric method based on reduction of a soluble tetrazolium salt, 2,3-bis [2-methoxy-4-nitro-5-[(sulfenylamino) carbonyl]-2H-tetrazolium-hydroxide], for antifungal susceptibility testing of Aspergillus species. J Clin Microbiol 2001, 39:4256-4263.

15. Meshulam T, Levitz SM, Christin L, Diamond RD: A simplified new assay for assessment of fungal cell damage with the tetrazolium dye, $(2,3)$-bis-(2methoxy-4-nitro-5-sulphenyl)-(2H)-tetrazolium-5-carboxanilide (XTT). J Infect Dis 1995, 172:1153-1156.

16. Tellier R, Krajden M, Grigoriew GA, Campbell I: Innovative endpoint determination system for antifungal susceptibility testing of yeasts. Antimicrob Agents Chemother 1992, 36:1619-1625.

17. Goodwin C, Holt SJ, Downes S, Marshall NJ: Microculture tetrazolium assays: a comparison between two new tetrazolium salts, XTT and MTS. J Immunol Methods 1995, 179:95-103.

18. Ramage G, Vandewalle K, Wickes BL, Lopez-Ribot JL: Standardized method for in vitro antifungal susceptibility testing of Candida albicans biofilms. Antimicrob Agents Chemother 2001, 45:2475-2479.

19. Scudiero D, Shoemaker RH, Paull KD, Monks A, Tierney S, Nofziger TH, Currens MJ, Seniff D, Boyd MR: Evaluation of a soluble tetrazolium/ formazan assay for cell growth and drug sensitivity in culture using human and other tumor cell lines. Cancer Res 1988, 48:4827-4833.

20. Stevens M, Olsen SC: Comparative analysis of using MTT and XTT in colorimetric assays for quantitating bovine neutrophil bactericidal activity. J Immunol Methods 1993, 157:225-231.

21. Mosmann T: Rapid colorimetric assay for cellular growth and survival: application to proliferation and cytotoxicity assays. J Immunol Methods 1983, 65:55-63.

22. Roehm N, Rodgers GH, Hatfield SM, Glasebrook AL: An improved colorimetric assay for cell proliferation and viability utilizing the tetrazolium salt XTT. J Immunol Methods 1991, 142:257-265.

23. Winn R, Roilides E, Simitsopoulou M, Lyman CA, Maloukou A, Walsh TJ: Selective effects of interleukin (IL)-15 on antifungal activity and IL-8 release by polymorphonuclear leukocytes in response to hyphae of Aspergillus species. J Infect Dis 2003, 188:585-590.

24. McCluskey C, Quinn JP, McGrath JW: An evaluation of three newgeneration tetrazolium salts for the measurement of respiratory activity in activated sludge microorganisms. Microb Ecol 2005, 49:379-387.

25. Maneu V, Cervera AM, Martinez JP, Gozalbo D: Molecular cloning and characterization of a Candida albicans gene (EFB1) coding for the elongation factor EF-1 beta. FEMS Microbiol Lett 1996, 145:157-162.

26. Brummer E, Sugar AM, Stevens DA: Enhanced oxidative burst in immunologically activated but not elicited polymorphonuclear leukocytes correlates with fungicidal activity. Infect Immun 1985 49:396-401.

27. Lyman C, Simons ER, Melnick DA, Diamond RD: Unopsonized Candida albicans hyphae stimulate a neutrophil respiratory burst and a cytosolic calcium flux without membrane depolarization. J Infect Dis 1987, 156:770-776.

28. Katragkou A, Kruhlak MJ, Simitsopoulou M, Chatzimoschou A, Taparkou A, Cotten CJ, Paliogianni F, Diza-Mataftsi E, Tsantali C, Walsh TJ, et al: Interactions between human phagocytes and Candida albicans biofilms alone and in combination with antifungal agents. J Infect Dis 2010, 201: (12):1941-1949.

29. Chimento A, Cacciola SO, Garbelotto M: Detection of mRNA by Reverse Transcription PCR as an Indicator of Viability in Phytophthora ramorum. Proceedings of the Sudden Oak Death Third Science Symposium Santa Rosa, California; 2007.

30. Martinez A, Lahiri R, Pittman TL: Molecular determination of Mycobacterium leprae viability by use of real-time PCR. J Clin Microbiol 2009, 47:2124-2130.

31. Varughese E, Wymer LJ, Haugland RA: An integrated culture and real-time PCR method to assess viability of disinfectant treated Bacillus spores using robotics and the MPN quantification method. J Microbiol Meth 2007, 71:66-70.

32. Hao B, Clancy C, Cheng S, Raman S, Iczkowski K, Nguyen M: Candida albicans RFX2 encodes a DNA binding protein involved in DNA damage responses, morphogenesis, and virulence. Eukaryot Cell 2009, 8:627-639.

33. Khot P, Suci PA, Miller RL, Nelson RD, Tyler BJ: A small subpopulation of blastospores in Candida albicans biofilms exhibit resistance to amphotericin $B$ associated with differential regulation of ergosterol and $\beta-1,6-$ glucan pathway genes. Antimicrob Agents Chemother 2006 50:3708-3716.

34. Taylor B, Hannemann $H$, Sehnal M, Biesemeier A, Schweizer A, Rollinghoff M, Schroppel K: Induction of SAP7 correlates with virulence in an intravenous infection model of candidiasis but not in a vaginal infection model in mice. Infect Immun 2005, 73:7061-7063.

35. Theiss S, Ishdorj G, Brenot A, Kretschmar M, Lan CY, Nichterlein T, Hacker J, Nigam S, Agabian N, Kohler GA: Inactivation of the phospholipase B gene PLB5 in wild-type Candida albicans reduces cell-associated phospholipase A2 activity and attenuates virulence. Int J Med Microbiol 2006, 296:405-420

36. Uppuluri P, Chaturvedi AK, Lopez-Ribot JL: Design of a simplemodel of Candida albicans biofilms formed under conditions of flow: development, architecture, and drug Resistance. Mycopathologia 2009, 168:101-109.

37. Vogel M, Hartmann T, Köberle M, Treiber M, Autenrieth I, Schumacher U: Rifampicin induces MDR1 expression in Candida albicans. J Antimicrob Chemother 2008, 61:541-547.

38. Fonzi WAMI: Isogenic strain construction and gene mapping in Candida albicans. Genetics 1993, 134:717-728.

39. Dongari-Bagtzoglou $\mathrm{A}$, Kashleva $\mathrm{H}$ : Development of a highly reproducible 3 D organotypic model of the oral mucosa. Nature Protocols 2006, 1(4):2012-2018.

40. Nett J, Sanchez H, Cain MT, Andes DR: Genetic basis of Candida biofilm resistance due to drug-sequestering matrix glucan. J Infect Dis 2010, 202:171-175.

41. Nett JE, Crawford K, Marchillo K, Andes DR: Role of Fks1p and matrix glucan in Candida albicans biofilm resistance to an echinocandin, pyrimidine, and polyene. Antimicrob Agents Chemother 54(8):3505-3508.

doi:10.1186/1471-2180-11-93

Cite this article as: Xie et al:: A quantitative real-time RT-PCR assay for mature C. albicans biofilms. BMC Microbiology 2011 11:93.

\section{Submit your next manuscript to BioMed Central and take full advantage of:}

- Convenient online submission

- Thorough peer review

- No space constraints or color figure charges

- Immediate publication on acceptance

- Inclusion in PubMed, CAS, Scopus and Google Scholar

- Research which is freely available for redistribution

Submit your manuscript at www.biomedcentral.com/submit
C Biomed Central 